\title{
Synthesis of Amphiphilic Graftcopolymers from Polystyrene Macromonomer
}

\author{
Yuya Yamashita, Koichi Ito, * Haruki Mizuno, \\ and Keisuke OKADA \\ Department of Synthetic Chemistry, Faculty of Engineering, \\ Nagoya University, Nagoya 464, Japan.
}

(Received June 30, 1981)

\begin{abstract}
Graftcopolymers of well-defined structure and composition were prepared by the radical copolymerization of polystyrene macromonomers with functional comonomers. The macromonomer was prepared by the polymerization of styrene in the presence of monoiodoacetic acid as a chain transfer agent, followed by an end-capping reaction with glycidyl methacrylate. In the case of 2-hydroxyethyl methacrylate as a comonomer, hydrophilic graftcopolymer soluble in polar solvent was obtained and characterized by thin layer chromatography. In the case of perfluoroalkyl acrylate as a comonomer, hydrophobic graftcopolymer soluble in ordinary solvent was obtained.

KEY WORDS Graftcopolymer / Macromonomer / Styrene / Hydroxyethyl Methacrylate / Fluoroacrylate /
\end{abstract}

Recently, the synthesis of tailored graftcopolymers by the macromonomer technique has been of interest in connection with the ease of the combination of a wide variety of monomers. The macromonomer technique consists of the introduction of branches by the copolymerization of the preformed macromonomers with various comonomers to obtain well-defined graftcopolymers; the number and length of branches in the backbone polymer can be controlled. ${ }^{1,2}$ We have already reported on the syntheses and characterization of methyl methacrylate-stearyl methacrylate graftcopolymers. ${ }^{3}$ This paper reports on the synthesis of amphiphilic graftcopolymers from polystyrene macromonomer prepared by free radical polymerization using a chain transfer agent. As functional comonomers, 2-hydroxyethyl methacrylate and perfluoroalkyl acrylate was used to obtain hydrophilic and hydrophobic graftcopolymers, respectively. The method of preparation is shown in Scheme I.

\section{EXPERIMENTAL}

\section{Materials}

Styrene (St), methyl methacrylate (MMA), 2hydroxyethyl methacrylate (HEMA) and glycidyl methacrylate (GMA) were purified by vacuum distillation. Azobisisobutyronitrile (AIBN) and hydroquinone were recrystallized from methanol. All solvents were dried and distilled before use. Monoiodoacetic acid and lauryldimethylamine were used as received. Perfluoroalkyl acrylate (FA) was kindly provided by Asahi Glass Co. and distilled before use. The perfluoroalkyl acrylate is a commercial mixture of

$$
\mathrm{CH}_{2}=\mathrm{CHCOOCH}_{2} \mathrm{CH}_{2} \mathrm{C}_{n} \mathrm{~F}_{2 n+1} \text {, }
$$

with the average number $n$ equal to 8.82 .

\section{Prepolymers}

St, AIBN, and monoiodoacetic acid were weighed into an ampule and degassed and sealed under vacuum. Polymerization was carried out in bulk at $60^{\circ} \mathrm{C}$ to an appropriate conversion. The polymer

* Present address: School of Material Science, Toyohashi University of Technology, Toyohashi 440, Japan. 
Scheme I

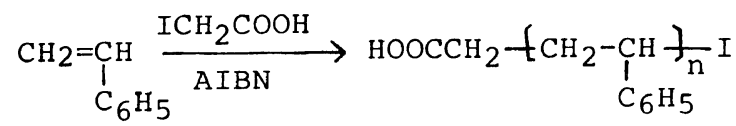

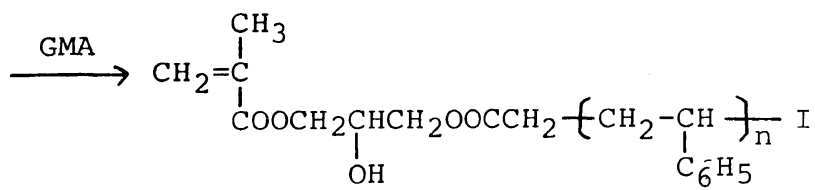

copolymerization with

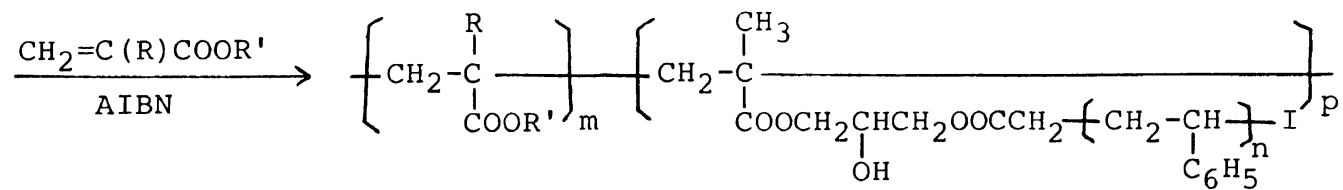

$1 \mathrm{R}=\mathrm{CH}_{3}, \mathrm{R}^{\prime}=\mathrm{CH}_{2} \mathrm{CH}_{2} \mathrm{OH}$

$2 \mathrm{R}=\mathrm{H}, \quad \mathrm{R}^{\prime}=\mathrm{CH}_{2} \mathrm{CH}_{2} \mathrm{C}_{n} \mathrm{~F}_{2 \mathrm{n}+1} \quad(\overline{\mathrm{n}}=8.82)$

was precipitated into methanol, purified three times by reprecipitation from benzene into methanol and dried under vacuum. The carboxyl group content was determined by titrating the polymer in dimethylformamide (DMF) with $0.1 N$ potassium hydroxide aqueous solution, using thymol blue as an indicator. The agreement of $M_{n}$ observed by VPO in benzene with that calculated by titration confirmed the purity of the carboxylic terminated prepolymer. GPC measurement in tetrahydrofuran (THF) was used to check the molecular weight distribution.

\section{Macromonomers}

The carboxylic terminated prepolymer was reacted with glycidyl methacrylate $(50 \mathrm{~mol} \%$ excess) at $140^{\circ} \mathrm{C}$ in xylene with small amounts of hydroquinone and lauryldimethylamine to prepare the macromonomer having a methacryl group at one end. The reaction was carried out in an ampule under nitrogen to prevent coloration. The polymer was precipitated into methanol, purified three times by reprecipitation from benzene into methanol and dried under vacuum. It was characterized by VPO and GPC measurement.

\section{Graftcopolymers}

The St macromonomer thus obtained was copolymerized in an ampule with various comonomers to complete the conversion to various graftcopolymers using AIBN for several days in a homogeneous solution. In the case of HEMA as a comonomer, DMF was chosen as the solvent and the graftcopolymer was precipitated into diethyl ether. In the case of FA as a comonomer, benzotrifluoride was chosen as the solvent and the graftcopolymer was precipitated into cyclohexane. The graftcopolymer was characterized by elemental analysis and GPC.

Characterization of the St-HEMA graftcopolymer was carried out by the following procedure. The PSt content was analyzed by UV spectrometry in the DMF or THF solvent, using the calibration curve for PSt. Soxhlet extraction of the graftcopolymer was carried out for 6 hours, first with cyclohexane to remove homopoly-St and then with methanol to remove homopoly-HEMA. In the case of MMA-rich ternary graftcopolymers consisting of St-(HEMA-co-MMA), acetonitrile was used in place of methanol. Thin layer chromatog- 
raphy was carried out with a silica gel plate (Eastman Kodak 1381) and fluorescent indicator (No. 6060). THF was used as a spotting solvent and either methanol or ethyl acetate was used as the developing solvent.

\section{RESULTS AND DISCUSSION}

\section{Synthesis of Macromonomer}

St macromonomer can be obtained by endcapping the polystyrene living anion with methacryloyl chloride. ${ }^{2}$ In the present work, free radical polymerization was adopted as a practical procedure for preparing prepolymers. Various chain transfer agents were compared in synthesizing carboxylic-terminated St prepolymers. Thioglycolic acid and tribromoacetic acid were found to be too reactive in the chain transfer reaction. The reported values for the chain transfer constants $C_{\mathrm{s}}$ are 14 and 3 , respectively. ${ }^{4}$ It was found that carboxylic-terminated PSt could be obtained at a low conversion by a chain transfer reaction, but an increase in mo- lecular weight was observed at a higher conversion due to consumption of the chain transfer agent, resulting in the presence of impure materials. When monoiodoacetic acid as a chain transfer agent was used, a carboxylic-terminated prepolymer of molecular weight range $2000-8000$ was easily obtained at moderate conversion as expected from its $C_{\mathrm{s}}$ value of $0.8 .^{4}$ Table $\mathrm{I}$ gives the results of the preparation of several prepolymers which were characterized by molecular weight determination with GPC, VPO, and end group titration. The approximate chain transfer constant $C_{\mathrm{s}}$ was calculated to be from $0.41-0.51$, using the integrated Mayo equation for the high conversion system.

The terminal carboxyl group of St prepolymer was reacted with glycidyl methacrylate at $140^{\circ} \mathrm{C}$ in xylene in the presence of hydroquinone and lauryldimethylamine. After $4 \mathrm{~h}$, the reaction proceeded nearly $90 \%$ and the macromonomer was characterized by VPO and GPC. It was difficult for the purity of the macromonomer to exceed $90 \%$ especially when the conversion was high in the prep-

Table I. Synthesis of St prepolymer

\begin{tabular}{|c|c|c|c|c|c|c|c|}
\hline \multirow{2}{*}{ No. } & \multirow{2}{*}{$\frac{[\mathrm{S}]_{0}^{\mathrm{b}}}{[\mathrm{M}]_{0}}$} & \multirow{2}{*}{$\begin{array}{l}\text { AIBN } \\
\mathrm{mol}^{\circ} \%\end{array}$} & \multirow{2}{*}{$\frac{\text { Time }}{h}$} & \multirow{2}{*}{$\frac{\text { Conversion }}{w t \%}$} & \multicolumn{2}{|c|}{$M_{n}$} & \multirow{2}{*}{$C_{\mathrm{s}}^{\mathrm{d}}$} \\
\hline & & & & & Tit. $^{c}$ & VPO & \\
\hline 31 & 0.0609 & 0.2 & 7.0 & 22.4 & 3300 & 4000 & 0.52 \\
\hline 32 & 0.0617 & 0.2 & 7.5 & 24.7 & 3500 & 3800 & 0.47 \\
\hline 34 & 0.0637 & 0.4 & 5.7 & 25.1 & 3200 & 3300 & 0.51 \\
\hline 36 & 0.0281 & 0.4 & 3.0 & 17.1 & 6080 & 7660 & 0.61 \\
\hline 38 & 0.0535 & 0.4 & 4.5 & 19.1 & 4670 & 4300 & 0.41 \\
\hline
\end{tabular}

a Bulk, $60^{\circ} \mathrm{C}$.

b Molar feed ratio of monoiodoacetic acid to monomer.

c $M_{n}$ by carboxyl end group titration assuming one $\mathrm{COOH}$ per molecule.

d Chain transfer constant calculated from $C_{\mathrm{s}}=\log \left(1-\alpha[\mathrm{M}]_{0} / n[\mathrm{~S}]_{0}\right) / \log (1-\alpha): \alpha$, conversion; $n$, degree of polymerization by titration.

Table II. Synthesis of St macromonomer ${ }^{\mathrm{a}}$

\begin{tabular}{|c|c|c|c|c|c|}
\hline \multirow{2}{*}{ No. } & \multirow{2}{*}{$\begin{array}{l}M_{n} \text { of PSt } \\
\text { VPO }\end{array}$} & \multirow{2}{*}{$\frac{\text { Time }}{\mathrm{h}}$} & \multirow{2}{*}{$\begin{array}{l}\text { Yield } \\
w t \%\end{array}$} & \multirow{2}{*}{$\begin{array}{c}\text { Unreacted } \mathrm{PSt}^{\mathrm{b}} \\
w \mathrm{wt} \%\end{array}$} & \multirow{2}{*}{$\begin{array}{c}M_{n} \text { of macromonomer } \\
\text { VPO }\end{array}$} \\
\hline & & & & & \\
\hline 332 & 3800 & 5 & 90.4 & 10.0 & 5200 \\
\hline 341 & 3300 & 4 & 89.9 & 27.0 & 4300 \\
\hline 361 & 7660 & 4 & 94.6 & 7.0 & 7690 \\
\hline 381 & 4300 & 4 & 94.6 & 5.0 & 4900 \\
\hline
\end{tabular}

${ }^{a}$ In xylene, $140^{\circ} \mathrm{C}$.

b By titration of $\mathrm{COOH}$ group. 
aration of the prepolymer. The results are shown in Table II.

\section{Preparation of Graftcopolymer}

The St macromonomer thus obtained was copolymerized using AIBN with hydrophilic or hydrophobic comonomers to complete conversions so as to obtain amphiphilic graftcopolymers at $60^{\circ} \mathrm{C}$ for several days in a homogeneous solution. In the case of HEMA as a hydrophilic comonomer, DMF was used as the solvent, since gelation was observed in THF. In Table III is shown binary graftcopolymerization and in Table IV, ternary graftcopolymerization. The graftcopolymer was soluble in various organic solvents, indicating the amphiphilic nature of the graftcopolymer. The contaminated St prepolymer and unreacted macromonomer were removed by reprecipitation from dimethylformamide, and placed in diethyl ether. The St content in the graftcopolymer was obtained from elemental analysis and UV spectrometry. The experimental results show a decrease in St content in the graftcopolymer compared with the initial feed ratios. To explain this, the reactivity of St macromonomer was studied. Figure 1 shows the copolymer composition curve of St macromonomer $\left(M_{2}\right)$ and HEMA $\left(M_{1}\right)$. The copolymerization was terminated at low conversion and the

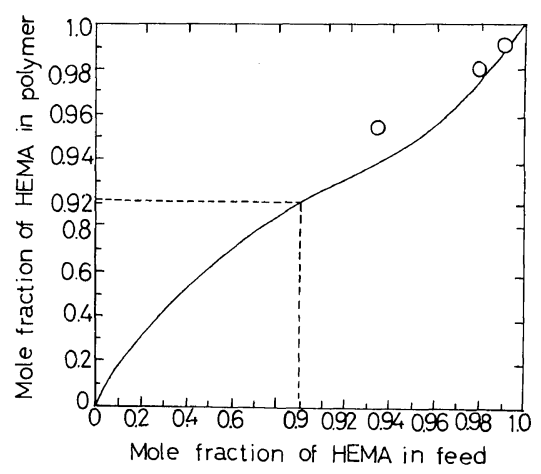

Figure 1. Copolymer composition curve for St macromonomer $\left(\mathrm{M}_{2}\right)$ and HEMA $\left(\mathrm{M}_{1}\right): \bigcirc$, copolymerization in DMF at $60^{\circ} \mathrm{C}$ with AIBN; -, Calculated by $r_{1}=1.0$, $r_{2}=0.29$ for HEMA $\left(\mathrm{M}_{1}\right)$-MMA $\left(\mathrm{M}_{2}\right)$, bulk at $60^{\circ} \mathrm{C}$ with BPO.

Table III. Preparation of St-HEMA graftcopolymers ${ }^{a}$

\begin{tabular}{|c|c|c|c|c|c|c|c|}
\hline \multirow{3}{*}{ No. } & \multicolumn{3}{|c|}{ PSt in feed } & \multicolumn{4}{|c|}{ Graftcopolymer } \\
\hline & \multirow{2}{*}{$\begin{array}{c}M_{n} \\
\text { VPO }\end{array}$} & \multirow{2}{*}{$\mathrm{wt} \%$} & \multirow{2}{*}{$\mathrm{mol}^{\%} \%$} & \multirow{2}{*}{$\frac{\text { Yield }}{w t \%}$} & \multirow{2}{*}{$\begin{array}{c}M_{n} \\
\mathrm{GPC}\end{array}$} & \multicolumn{2}{|c|}{ PSt wt $\%$ from } \\
\hline & & & & & & $\mathrm{C} \%$ & UV \\
\hline 3412 & 4300 & 68.7 & 6.2 & 69.0 & 14000 & 46.2 & - \\
\hline 3611 & 7690 & 23.9 & 0.7 & 79.2 & - & 11.2 & 18.7 \\
\hline 3612 & 7690 & 47.9 & 1.5 & 81.8 & 16000 & 34.3 & 38.9 \\
\hline
\end{tabular}

a $60^{\circ} \mathrm{C}$ in DMF, AIBN $0.2 \mathrm{~mol} \%, 7$ days.

Table IV. Preparation of St-(HEMA-co-MMA) graftcopolymers ${ }^{a}$

\begin{tabular}{|c|c|c|c|c|c|c|c|c|c|c|}
\hline \multirow{3}{*}{ No. } & \multicolumn{5}{|c|}{ Feed } & \multicolumn{5}{|c|}{ Graftcopolymer } \\
\hline & \multirow{2}{*}{$\begin{array}{c}M_{n}, \text { PSt } \\
\text { VPO }\end{array}$} & \multicolumn{2}{|c|}{$w t \%$} & \multicolumn{2}{|c|}{$\mathrm{mol} \%$} & \multirow{2}{*}{$\frac{\text { Yield }}{w t \%}$} & \multirow{2}{*}{$\begin{array}{c}M_{n} \\
\mathrm{GPC}\end{array}$} & \multicolumn{2}{|c|}{$\mathrm{C} \%$} & \multirow{2}{*}{$\frac{\text { PSt }}{w t \%, U V}$} \\
\hline & & PSt & HEMA & PSt & HEMA & & & obs. & calcd. $^{\mathbf{b}}$ & \\
\hline 3414 & 4300 & 20.0 & 39.9 & 0.65 & 43.0 & 91.4 & 44300 & 69.6 & 64.6 & 21.7 \\
\hline 3415 & 4300 & 18.2 & 53.0 & 0.64 & 58.9 & 85.3 & 25300 & 60.6 & 63.5 & 12.7 \\
\hline 3614 & 7690 & 23.1 & 39.0 & 0.44 & 43.5 & 84.1 & 40900 & 63.1 & 65.6 & 16.7 \\
\hline 3615 & 7690 & 24.0 & 51.6 & 0.48 & 61.6 & 87.7 & 37500 & 61.6 & 65.3 & 15.7 \\
\hline
\end{tabular}

a $60^{\circ} \mathrm{C}$ in DMF, AIBN $0.2 \mathrm{~mol} \%, 7$ days.

b Assuming a composition the same as that of the feed. 


\section{Amphilic Graftcopolymers}

Table V. Fractionation of graftcopolymers ${ }^{\mathrm{a}}$ (Soxhlet extraction)

St-HEMA graftcopolymer

\begin{tabular}{|c|c|c|c|c|c|}
\hline \multirow{2}{*}{ No. } & \multirow{2}{*}{$\begin{array}{c}\text { PSt } \\
\mathrm{wt}^{\circ} \%\end{array}$} & \multicolumn{2}{|c|}{$\mathrm{MeOH}$ insoluble part } & \multicolumn{2}{|c|}{$\mathrm{MeOH}$ soluble part } \\
\hline & & $\mathrm{wt} \%$ & PSt $w t^{\circ} \%^{b}$ & $w t \%$ & IR \\
\hline 3611 & 18.7 & 62.6 & 22.7 & 37.4 & PHEMA \\
\hline 3612 & 38.9 & 91.0 & 37.9 & 9.0 & PHEMA \\
\hline
\end{tabular}

St-(HEMA-co-MMA) graftcopolymer

\begin{tabular}{|c|c|c|c|c|c|}
\hline \multirow{2}{*}{ No. } & \multirow{2}{*}{$\begin{array}{c}\text { PSt } \\
\mathrm{wt}^{\mathrm{o}} \% \mathrm{~b}\end{array}$} & \multicolumn{2}{|c|}{$\mathrm{MeOH}$ insoluble part } & \multicolumn{2}{|c|}{$\mathrm{MeOH}$ soluble part } \\
\hline & & $\mathrm{wt} \%$ & PSt $w t^{\circ}{ }^{b}$ & $\mathrm{wt} \%$ & IR \\
\hline 3415 & 12.7 & 74.1 & 13.6 & 25.9 & Graft \\
\hline 3615 & 15.7 & 71.0 & 18.3 & 29.0 & Graft \\
\hline
\end{tabular}

a Insoluble in cyclohexane.

b Determined by UV.

copolymer was precipitated in diethyl ether to remove the unreacted macromonomer. The experimental points lay well on the calculated curve for the copolymerization of HEMA and MMA $\left(r_{1}=1.0, r_{2}=0.29\right)$ in HEMA rich region. ${ }^{5}$ The reactivity of the St macromonomer is not different from MMA except for the macromonomer-rich feed ratios, since the poly-St segment is remote from the reacting methacrylate group. Thus, the decrease in St content in the graftcopolymer is ascribed to the loss of St rich polymer soluble in diethyl ether, presumably because of the contaminated unreactive St prepolymer in the macromonomer. The purity of the graftcopolymer in Tables III and IV was checked by GPC and TLC. Typical GPC chromatograms are shown in Figure 2. By using UV and RI detectors, it was proved that PSt segment was evenly distributed in the whole polymer.

The results of the fractionation of the graftcopolymer are shown in Table V. Soxhlet extraction with cyclohexane removed trace amounts of PSt and further extraction with methanol removed considerable amounts of HEMA rich polymers. Thin layer chromatography was useful in characterizing the graftcopolymers. Figure 3 shows that the methanol insoluble fraction is not developed in TLC either by methanol or ethyl acetate, thus confirming the different behavior of the

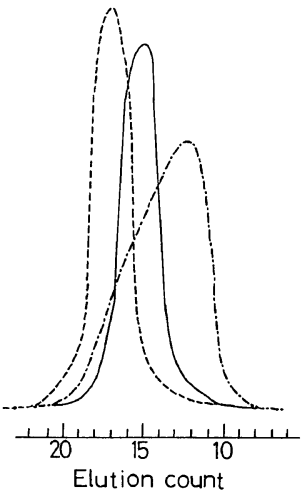

Figure 2. GPC chromatogram for graftcopolymers: -.---., macromonomer (No. 341) $M_{n}=4300$; - , StHEMA graftcopolymer (No. 3412) $M_{n}=14000$, PSt (feed) $68.7 \mathrm{wt} \%$; - - , St-(HEMA-co-MMA) graftcopolymer (No. 3414) $M_{n}=44300$, PSt (feed) $20.0 \mathrm{wt} \%$, HEMA (feed) $39.9 \mathrm{wt} \%$.
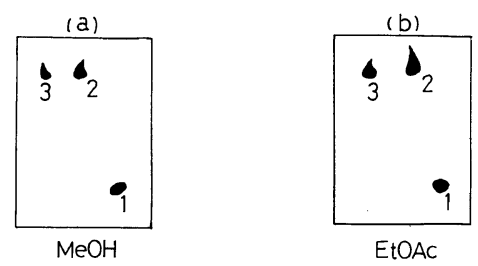

Figure 3. TLC chromatogram for ternary graftcopolymers. (a): 1, PHEMA; 2, PMMA; 3, G3615 (MeOH insoluble part). (b): 1, PSt; 2, PMMA, 3, G3615 (MeOH insoluble part). 
fractions from PSt, poly(MMA) or poly(HEMA). From the above results, the formation of the graftcopolymer was established. The purity of the graftcopolymer was higher in the case of a lower HEMA feed ratio and a ternary system might be preferred.

A hydrophobic graftcopolymer was prepared using perfluoroalkyl acrylate as the comonomer. Benzotrifluoride was used as the solvent in the polymerization and the polymer was precipitated into cyclohexane. PSt macromonomer of $M_{n}=4900$ (No. 381) was copolymerized with an equal amount of perfluoroalkyl acrylate at $60^{\circ} \mathrm{C}$, using $1 \mathrm{~mol} \%$ of AIBN. After five days, the yield of the graftcopolymer was $60 \%$. The graftcopolymer was soluble in THF, diethyl ether, warm cyclohexane and benzotrifluoride, indicating the amphiphilic nature of the copolymer; the foaming solution resulted from the high surface activity of the graftcopolymer. GPC measurement with UV and RI detectors proved that the graftcopolymer was free of unreacted macromonomer and that the distribution of the PSt branches was uniform throughout the graftcopolymer. $M_{n}$ was 40,000 and the PSt content was $50.9 \mathrm{wt} \%$. The observed difference in solubility between the copolymer and the homopolymer suggests the formation of the graftcopolymer, but further study seems necessary to find a means for the purification of the graftcopolymer.

\section{REFERENCES}

1. F. A. Waite, J. Oil Color Chem. Assoc., 54, 342 (1971).

2. R. Milkovich, Polym. Prepr., Am. Chem. Soc., Div. Polym. Chem., 21, 40 (1980).

3. K. Ito, N. Usami, and Y. Yamashita, Macromolecules, 13, 216 (1980).

4. J. Brandrup and E. H. Immergut, "Polymer Handbook," II-57, John Wiley, New York, 1975.

5. I. K. Varma and S. Patnaik, Eur. Polym. J., 12, 259 (1976). 